\section{Factors associated with treatment failure, dropout, and death in a cohort of tuberculosis patients in Recife, Pernambuco State, Brazil}

\author{
Fatores associados com falência terapêutica, \\ abandono e óbito em uma coorte de pacientes \\ com tuberculose acompanhados no Recife, \\ Pernambuco, Brasil
}

\author{
Maria de Fátima Pessoa Militão de \\ Albuquerque 1,2 \\ Ricardo Arraes de Alencar Ximenes 2,3 \\ Norma Lucena-Silva ${ }^{1}$ \\ Wayner Vieira de Souza 1 \\ Andréa Tavares Dantas 4 \\ Odimariles Maria Souza Dantas 2 \\ Laura Cunha Rodrigues 5
}

\author{
${ }^{1}$ Centro de Pesquisas Aggeu \\ Magalhães, Fundação \\ Oswaldo Cruz, Recife, Brasil. \\ 2 Departamento de Medicina \\ Clínica, Universidade Federal \\ de Pernambuco, Recife, \\ Brasil. \\ 3 Departamento de Clínica \\ Médica, Universidade de \\ Pernambuco, Recife, Brasil. \\ ${ }^{4}$ Hospital das Clínicas, \\ Universidade Federal de \\ Pernambuco, Recife, Brasil. \\ ${ }^{5}$ London School of Hygiene \\ and Tropical Medicine, \\ London, U.K. \\ Correspondência \\ M. F. P. M. Albuquerque \\ Departamento de Estudos \\ em Saúde Coletiva, Centro de \\ Pesquisas Aggeu Magalhães, \\ Fundação Oswaldo Cruz. \\ Av. Dezessete de Agosto 1820 , \\ apto. 301, Recife, $P E$ \\ 52061-540, Brasil. \\ militao@cpqam.fiocruz.br
}

\begin{abstract}
A cohort of cases initiating tuberculosis treatment from May 2001 to July 2003 was followed in Recife, Pernambuco State, Brazil, to investigate biological, clinical, social, lifestyle, and healthcare access factors associated with three negative tuberculosis treatment outcomes (treatment failure, dropout, and death) separately and as a group. Treatment failure was associated with treatment delay, illiteracy, and alcohol consumption. Factors associated with dropout were age, prior TB treatment, and illiteracy. Death was associated with age, treatment delay, HIV co-infection, and head of family's income. Main factors associated with negative treatment outcomes as a whole were age, HIV co-infection, illiteracy, alcoholism, and prior TB treatment. We suggest the following strategies to increase cure rates: further training of the Family Health Program personnel in TB control, awareness-raising on the need to tailor their activities to special care for cases (e.g., literacy training); targeting use of directly observed therapy for higher risk groups; establishment of a flexible referral scheme to handle technical and psychosocial problems, including alcoholism; and increased collaboration with the HIVIAIDS program.
\end{abstract}

Tuberculosis; Risk Factors; Treatment Failure

\section{Introduction}

The annual tuberculosis (TB) incidence rate is high in the city of Recife, Pernambuco State, Brazil, and has been constant in recent years at approximately 100 per 100,000 inhabitants. In Brazil, case finding is mostly passive, and diagnosis is mainly based on sputum smear examination in patients presenting cough of more than three weeks' duration ${ }^{1}$. Treatment (mainly selfadministered) is managed through outpatient services, and only the severely ill are hospitalized. The drug regimen for new cases includes pyrazinamide, isoniazid, and rifampicin for the first two months and isoniazid and rifampicin for the last four months. Re-treatment uses the same drugs as for new cases, plus ethambutol, for the full six months 1 . Directly observed therapy (DOT), rather than the wider DOTS strategy (which includes government commitment to TB control, case detection by sputum microscopy, supply of free drugs administered under direct observation for at least the first two months, and improved case management and monitoring of outcomes) has been introduced, but there are no clear criteria for including patients in the strategy. The TB control program is undergoing decentralization with the progressive transfer of activities from "TB health units" to Family Health Program (FHP) units and teams. The FHP is a new program in which teams of health professionals work in the community, linked to health 
units. Each team is responsible for approximately 3,200 residents of a specific geographical area 2,3.

The definitions vary for an "unsuccessful" outcome of TB treatment and the population in which it has been studied. Some definitions consider only noncompliance, while others combine all negative outcomes: treatment failure, noncompliance, and death 4,5,6,7,8,9. Determinants have included male gender 4,10 , older age 7 , migration 11, homelessness 11,12,13, history of incarceration 11,12, alcoholism 12,13, HIV infection $7,8,14,15,16$, intravenous drug use 12 , and decreased access to healthcare 4 .

The current study focuses on the association between all forms of unsuccessful TB treatment outcomes and biological, clinical, social, lifestyle, and healthcare access factors as part of a broader study on different aspects of TB control activities in Recife. Both new and previously treated cases were included.

\section{Methods}

The study population consisted of a cohort of TB cases newly diagnosed from May 2001 to July 2003, residing in Recife (cases were excluded if the final treatment outcome was not known). Patients at the primary health unit were invited to participate in the study as soon after diagnosis as possible. Those who agreed to participate signed an informed consent form and were interviewed by trained assistant nurses using a standard questionnaire, after which they had a sputum sample taken for examination and a blood sample drawn for HIV serology. Treatment outcome was ascertained from the health unit registry and from patients' medical records soon after the expected end of treatment. When the information was not found, a second search was conducted six months after the end of data collection.

An outcome was defined as successful if there was documented evidence of cure or completion of treatment. Unsuccessful outcomes were defined, following the Brazilian TB treatment criteria (similar to the World Health Organization guidelines), as: (i) treatment failure, consisting of a positive smear four months after beginning treatment; (ii) treatment dropout, defined as no contact with the TB treatment center within 30 days after a missed appointment; or (iii) death during treatment. TB treatment outcomes were analyzed both separately (treatment failure, dropout, or death) and jointly.

Target exposures included:

- Clinical and epidemiological factors: treatment delay, defined as the lag between onset of symptoms and start of treatment (the cut-off point followed Santos et al. 17); previous TB treatment; drug regimen; and HIV co-infection.

- Biological factors: age group and sex.

- Social factors: patient income; employment status; head-of-household's literacy status and income.

- Lifestyle: alcohol consumption (excessive alcohol consumption or alcoholism, classified respectively as those who drink every day or those who, once having started drinking, find it difficult to stop).

- Health services: whether the FHP was implemented in the health district including the patient's place of residence. Health district in which the health unit was located was considered only for the combined outcomes.

\section{Analysis}

Risk factors were investigated for each of the three negative TB treatment outcomes (treatment failure, dropout, and death) separately and as a group. The significance of these associations was tested using the chi-square test and $\mathrm{p}$ values. Variables with a univariate association showing a $p$ value $\leq 0.20$ were included in a multiple logistic regression analysis. Crude and adjusted ORs and 95\%CIs were calculated. The population-attributable risk percent (PAR\%) in the final model was estimated as PAR\% $=\mathrm{p}_{\mathrm{e}}(\mathrm{OR}-1) / \mathrm{p}_{\mathrm{e}}(\mathrm{OR}-1)+1 \mathrm{x}$ 100 , where OR was the adjusted odds ratio for each variable.

\section{Results}

Of the 1,555 cases, $10.2 \%$ were excluded because of change of diagnosis, transfer out, or lack of information on outcome. Among the remaining 1,396 patients ( $86.8 \%$ with the pulmonary form), 1,089 had successful outcomes (217 with documented cure and 872 with documented completion of treatment) and 307 had unsuccessful outcomes (33 failed treatment, 230 abandoned treatment, and 44 died) (Table 1). Only $30 \%$ of the patients agreed to have blood samples drawn for HIV serology.

\section{Prognostic factors for treatment failure in tuberculosis patients:}

Univariate analysis on the relationship between treatment failure and biological and clinical factors showed an association $(\mathrm{p}<0.20)$ with age group, treatment delay, prior TB treatment, and treatment with $\mathrm{PZA}+\mathrm{INH}+\mathrm{RMP}+\mathrm{EMB}$. Among the socioeconomic and lifestyle factors, illiteracy and excessive alcohol consumption (includ- 
Tuberculosis outcomes in Recife, Pernambuco, Brazil, 2001-2003 ( $N=1,555)$.

\begin{tabular}{|c|c|c|c|c|c|c|}
\hline \multirow[t]{2}{*}{ Outcomes } & \multicolumn{2}{|c|}{ Successful } & \multicolumn{2}{|c|}{ Unsuccessful } & \multicolumn{2}{|c|}{ Excluded from analysis } \\
\hline & $\mathbf{n}$ & $\%$ & $\mathbf{n}$ & $\%$ & $\mathbf{n}$ & $\%$ \\
\hline Documented cure & 217 & 14.0 & - & - & - & - \\
\hline Completion of treatment & 872 & 56.1 & - & - & - & - \\
\hline Total successful & 1,089 & 70.1 & & & & \\
\hline Treatment dropout & - & - & 230 & 14.8 & - & - \\
\hline Treatment failure & - & - & 33 & 2.1 & - & - \\
\hline Death & - & - & 44 & 2.8 & - & - \\
\hline Total unsuccessful & & & 307 & 19.7 & & \\
\hline Change of diagnosis & - & - & - & - & 10 & 0.6 \\
\hline Change of municipality & - & - & - & - & 46 & 3.0 \\
\hline Unknown & - & - & - & - & 103 & 6.6 \\
\hline Total excluded & & & & & 159 & 10.2 \\
\hline
\end{tabular}

ing alcoholism) were associated with treatment failure. Not having received visits by the Family Health team was also associated with treatment failure.

The following variables remained in the final multivariate model: treatment delay, illiteracy, and excessive alcohol consumption (Table 2).

\section{Prognostic factors for treatment} dropout in tuberculosis patients

Univariate analysis on the relationship between biological and clinical factors and treatment dropout showed significant association $(p<0.20)$ with age group, previous TB treatment, and treatment with $\mathrm{PZA}+\mathrm{INH}+\mathrm{RMP}+\mathrm{EMB}$. Among the socioeconomic and lifestyle factors, illiteracy and excessive alcohol consumption (including alcoholism) were associated with dropout.

The following variables remained in the final multivariate model: age group, previous TB treatment, and illiteracy (Table 3).

\section{Prognostic factors for death in} tuberculosis patients

Univariate analysis on the relationship between death and biological and clinical factors showed significant association $(\mathrm{p}<0.20)$ with age group, treatment delay, prior TB treatment, and HIV coinfection. Among the socioeconomic factors, unemployment and low income for head-of-household were associated with death. Not having received visits by the Family Health team was also associated with death.
The following variables remained in the final multivariate model: age group, treatment delay, HIV co-infection, and low income for head-ofhousehold (Table 4).

\section{Prognostic factors for grouped unsuccessful tuberculosis treatment outcomes}

According to the univariate analysis, biological and clinical factors associated with unsuccessful outcome $(p \leq 0.20)$ included age group, prior TB treatment, treatment with $\mathrm{PZA}+\mathrm{INH}+\mathrm{RMP}+\mathrm{EMB}$, and HIV co-infection. Social factors associated with unsuccessful outcome in the univariate analysis were illiteracy and head-of-household's low income. Univariate association between treatment outcome and lifestyle shows that alcoholics had approximately twice the risk of unsuccessful outcome as non-drinkers or social drinkers. The proportion of unsuccessful treatment varied among the six health districts: in District IV, $91.5 \%$ of treatment courses were successful, as compared to $71.2 \%$ in District VI.

In the final model (Table 5), variables significantly and independently associated with unsuccessful TB treatment were the 20-34 and 35-49-year age groups, prior TB treatment, illiteracy, HIV infection, alcoholism, and health district. The attributable risks of these factors were as follows: age $20-34$ years, $51 \%$, and $35-49$ years, $48.4 \%$; prior TB treatment, $41.2 \%$; illiteracy, $35.5 \%$; HIV infection, $68.3 \%$; and alcoholism, 51\%. The differences in treatment success between health districts did not decrease when the variables associated with individual patients were included, 
Multivariate analysis of factors associated with treatment failure in tuberculosis (TB) patients treated in Recife, Pernambuco, Brazil, $2001-2003$.

\begin{tabular}{|c|c|c|c|c|c|c|c|}
\hline & Crude OR & $95 \% \mathrm{Cl}$ & $p$ value & Adjusted OR & $95 \% \mathrm{Cl}$ & $p$ value & PAR\% \\
\hline Age group (years)* & & & 0.159 & & & & \\
\hline$<19$ & 1.00 & & & & & & \\
\hline $20-34$ & 1.53 & $0.31-7.67$ & 0.604 & & & & \\
\hline $35-49$ & 3.56 & $0.80-15.85$ & 0.095 & & & & \\
\hline $50-64$ & 4.32 & $0.92-20.30$ & 0.063 & & & & \\
\hline$\geq 65$ & 2.73 & $0.38-19.80$ & 0.320 & & & & \\
\hline \multicolumn{8}{|l|}{ Treatment delay (days) } \\
\hline$\leq 60$ & 1.00 & & & 1.00 & & & \\
\hline$>60$ & 6.06 & $1.84-19.98$ & 0.0031 & 4.44 & $1.30-15.11$ & 0.0170 & 68.1 \\
\hline \multicolumn{8}{|l|}{ Prior TB treatment } \\
\hline No & 1.00 & & & & & & \\
\hline Yes & 2.00 & $0.94-4.27$ & 0.073 & & & & \\
\hline \multicolumn{8}{|l|}{ Drug regimen } \\
\hline $\mathrm{PZA}+\mathrm{INH}+\mathrm{RMP}$ & 1.00 & & & & & & \\
\hline $\mathrm{PZA}+\mathrm{INH}+\mathrm{RMP}+\mathrm{BEM}$ & 3.24 & $1.35-7.79$ & 0.009 & & & & \\
\hline \multicolumn{8}{|l|}{ Literacy } \\
\hline Yes & 1.00 & & & 1.00 & & & \\
\hline No & 2.22 & $1.04-4.76$ & 0.039 & 2.84 & $1.20-6.70$ & 0.0175 & 23.0 \\
\hline Alcohol consumption & & & 0.009 & & & 0.0134 & \\
\hline Non-drinker & 1.00 & & & 1.00 & & & \\
\hline Social drinker & 0.39 & $0.13-1.16$ & 0.089 & 0.38 & $0.11-1.36$ & 0.1385 & \\
\hline Alcoholic & 2.50 & $1.05-5.94$ & 0.038 & 2.78 & $1.07-7.18$ & 0.0350 & 15.7 \\
\hline \multicolumn{8}{|l|}{ Family Health Program visits } \\
\hline Yes & 1.00 & & & & & & \\
\hline No & 1.83 & $0.84-3.99$ & 0.129 & & & & \\
\hline
\end{tabular}

${ }^{*} \chi^{2}$ for linear trend: $5.01, p=0.0252$

suggesting that the variations reflect healthcare practices rather than demographic composition.

\section{Discussion}

Treatment failure was associated with treatment delay, illiteracy, and alcohol consumption. Dropout was associated with age group, prior TB treatment, and illiteracy. Death was associated with age group, treatment delay, HIV co-infection, and head-of-household's low income. The main factors associated with combined unsuccessful treatment outcomes were age group, HIV co-infection, illiteracy, alcoholism, and prior TB treatment. The highest population-attributable risk percentages were related to HIV infection and alcohol consumption, both potentially modified by public health interventions.

The small number of cases of treatment failure and death limited the study, since the sample size may have lacked sufficient statistical power to reveal an association with some of the factors.
Treatment delay of more than 60 days was associated with treatment failure and death. Death associated with delay in TB detection has also been described in the former Yugoslavia 18. Treatment delay allows progression of the disease to a more severe clinical phase in which cure becomes more difficult.

Low socioeconomic status, expressed either as illiteracy or low income for the head of household, increased the risk of all three negative outcomes. The increased risk of death among individuals for whom the head-of-household's income was unknown probably reflects sporadic earnings. Illiteracy can reflect both poor access to information (an obstance for patients in this setting, which involves mainly written educational materials) and (given its strong association with low socioeconomic status) the inability to afford transportation to the health unit or losses in workdays. Because of social stigma, patients often prefer to be treated away from their place of residence 19. Such conditions contribute to irregular treatment, which may in turn lead to fail- 
Multivariate analysis of factors associated with treatment dropout in tuberculosis (TB) patients treated in Recife, Pernambuco, Brazil, $2001-2003$.

\begin{tabular}{|c|c|c|c|c|c|c|c|}
\hline & Crude OR & $95 \% \mathrm{Cl}$ & $p$ value & Adjusted OR & $95 \% \mathrm{Cl}$ & $p$ value & PAR $\%$ \\
\hline Age group (years) & & & 0.159 & & & & \\
\hline$<19$ & & & 0.003 & & & 0.015 & \\
\hline $20-34$ & 1.00 & & & 1.00 & & & \\
\hline $35-49$ & 2.42 & $1.43-4.10$ & 0.001 & 1.89 & $1.07-3.34$ & 0.028 & 21.6 \\
\hline $50-64$ & 2.25 & $1.32-3.83$ & 0.003 & 1.51 & $0.85-2.69$ & 0.163 & 13.6 \\
\hline$\geq 65$ & 1.47 & $0.79-2.71$ & 0.222 & 0.93 & $0.47-1.83$ & 0.829 & \\
\hline \multicolumn{8}{|l|}{ Prior TB treatment } \\
\hline No & 1.00 & & & 1.00 & & & \\
\hline Yes & 2.37 & $1.72-3.27$ & 0.000 & 2.16 & $1.51-3.12$ & 0.000 & 16.5 \\
\hline \multicolumn{8}{|l|}{ Drug regimen } \\
\hline PZA+INH+RMP & 1.00 & & & & & & \\
\hline$P Z A+I N H+R M P+B E M$ & 2.05 & $1.36-3.10$ & 0.001 & & & & \\
\hline \multicolumn{8}{|l|}{ Literacy } \\
\hline Yes & 1.00 & & & 1.00 & & & \\
\hline No & 1.69 & $1.20-2.37$ & 0.003 & 1.72 & $1.17-2.53$ & 0.006 & 10.1 \\
\hline Alcohol consumption & & & 0.067 & & & & \\
\hline Non-drinker & 1.00 & & & & & & \\
\hline Social drinker & 1.24 & $0.89-1.72$ & 0.203 & & & & \\
\hline Alcoholic & 1.68 & $1.07-2.65$ & 0.025 & & & & \\
\hline
\end{tabular}

ure. Although low income and poor formal education measure similar attributes, in this setting illiteracy represents a lower cut-off point on the social scale and is likely to be related to greater deprivation, which explains its closer association with negative prognosis. According to a study in Pelotas, a city in the South of Brazil, among the socioeconomic variables, only skin color (nonwhite) was associated with treatment noncompliance. The authors suggested that poorer patients, probably non-whites, are more likely to get the disease and to experience more adverse conditions, making personal and family adaptation to treatment more difficult 20,21 . The lack of association with other variables was probably due to the sample size. In another Brazilian study, at the ecological level, the correlation between TB death rates and poverty in São Paulo showed higher mortality in low-income areas 22 . A study that reviewed mortality data for all U.S. residents that died in 1990 with TB as the underlying cause of death or with TB listed anywhere on the death certificate as a contributing cause of death suggested a contribution to TB mortality by substance abuse (including alcohol) 23 .

Alcoholism, which the current study found to be associated with treatment failure and the combined negatives outcomes, is a classical factor 12,13 both for developing TB 24 and for poor treatment outcome.
HIV infection is also a widely described risk factor 7,8,14,15,16, and our results showed it was associated with death and unsuccessful outcome. Studies have shown that improved TB outcomes can be achieved through decentralization of treatment and the supply of an extended range of supervised DOT options (even in countries where HAART is not readily available, like Malawi 25) and the integration of the DOTs strategy with HIV/AIDS homecare 25,26,27. Some measures recommended by the WHO 28 could be implemented in this area, such as joint planning of some TB/HIV activities, periodic surveillance of HIV among TB patients, HIV counseling, and a rational regimen of treatment and follow-up for co-infected patients. The association with death during treatment in this setting is similar to other studies 29,30 .

A history of prior TB treatment, associated here with treatment failure and dropout, is a clear indication of the importance of properly completing treatment the first time around and monitoring patients, offering adequate support. Encouragingly, the fact that differences in treatment success between districts are not a consequence of case mix (the population composition being treated in different health districts), suggests room for improvement in the way TB control program services are run. Options on managing cases with social factors range from the 
Multivariate analysis of factors associated with death in tuberculosis (TB) patients treated in Recife, Pernambuco, Brazil, $2001-2003$.

\begin{tabular}{|c|c|c|c|c|c|c|c|}
\hline & Crude OR & $95 \% \mathrm{Cl}$ & $p$ value & Adjusted OR & $95 \% \mathrm{Cl}$ & $p$ value & PAR\% \\
\hline Age group (years) * & & & 0.032 & & & & \\
\hline$<19$ & 1.00 & & & & & & \\
\hline $20-34$ & 5.10 & $0.65-40.20$ & 0.122 & & & & \\
\hline $35-49$ & 7.63 & $1.00-58-27$ & 0.050 & & & & \\
\hline $50-64$ & 11.53 & $1.48-89.63$ & 0.019 & & & & \\
\hline$\geq 65$ & 16.38 & $1.93-138.75$ & 0.010 & & & & \\
\hline Age group ** & 1.63 & $1.24-2.14$ & 0.0003 & 1.75 & $1.31-2.36$ & 0.0002 & \\
\hline \multicolumn{8}{|l|}{ Treatment delay (days) } \\
\hline$\leq 60$ & 1.00 & & & 1.00 & & & \\
\hline$>60$ & 1.82 & $0.91-3.64$ & 0.0902 & 2.02 & $0.94-4.30$ & 0.0678 & 38.8 \\
\hline \multicolumn{8}{|l|}{ Prior TB treatment } \\
\hline No & 1.00 & & & & & & \\
\hline Yes & 1.83 & $0.92-3.62$ & 0.083 & & & & \\
\hline HIV infection & & & 0.000 & & & 0.0000 & \\
\hline Negative & 1.00 & & & 1.00 & - & & \\
\hline Positive & 20.07 & $6.35-63.45$ & 0.000 & 24.52 & $7.14-84.22$ & 0.0000 & 29.7 \\
\hline Not tested & 1.96 & $0.81-4.76$ & 0.136 & 1.93 & $0.78-4.75$ & 0.1528 & \\
\hline \multicolumn{8}{|l|}{ Employment status } \\
\hline Employed & 1.00 & & & & & & \\
\hline Unemployed & 3.22 & $1.61-6.43$ & 0.004 & & & & \\
\hline \multicolumn{8}{|l|}{ Income of head of household } \\
\hline (times the minimum wage) & & & 0.0190 & & & 0.0426 & \\
\hline$\geq 2$ & 1.00 & & & 1.00 & & & \\
\hline$<2$ & 1.59 & $0.43-5.86$ & 0.4863 & 0.35 & $0.07-1.69$ & 0.1940 & \\
\hline Unknown & 3.57 & $1.08-11.83$ & 0.0372 & 1.81 & $0.85-3.87$ & 0.1207 & \\
\hline \multicolumn{8}{|l|}{ Family Health Program visits } \\
\hline Yes & 1.00 & & & & & & \\
\hline No & 1.73 & $0.87-3.43$ & 0.116 & & & & \\
\hline
\end{tabular}

\footnotetext{
* Categorical:
}

${ }^{* *}$ Continuous.

authoritarian approach 31 to the enabling, with comprehensive, tailored, support 32. Another possibility is further training of FHP personnel. Interestingly, prior TB chemotherapy was also associated with treatment dropout in HIV-positive subjects 33 .

Age was associated treatment failure, dropout, and death in the multivariate models. Aging was associated with increased odds of death, while the 20-49-year bracket was associated with increased odds of treatment failure and dropout. Dropout in the 29-49-year bracket is likely to be related to the demands of work activities, which may hinder attendance at clinics. Like our results, other authors 7 have described age $(>50)$ as an independent predictor of death.

Health personnel in the local units have still not developed the necessary skills to deal with the various psychosocial and technical problems that can arise. This is an opportunity to offer further training based on the results of the current study. One alternative is to train the teams to implement a form of DOT tailored to specific groups (alcoholics, illiterates, the poor, and patients with prior treatment or HIV infection). This alone may not be sufficient, as there is evidence that DOTS can fail to increase the proportion of satisfactory outcomes in high-risk populations ${ }^{12}$. Additional measures could include developing appropriate educational materials for illiterate patients and evaluation of practice in both the successful and less successful health districts, thereby leading to widespread adoption of practices from the successful clinics.

Unlike other studies, we did not find treatment failure to be associated with gender 4,10 . Uplekar et al. 10, reviewing the literature, found that women generally tend to comply better and 
Multivariate analysis of prognostic factors associated with combined unsuccessful outcomes of tuberculosis (TB) treatment in Recife, Pernambuco, Brazil, 20012003

$(N=1,396)$.

\begin{tabular}{|c|c|c|c|c|c|c|c|}
\hline & Crude OR & $95 \% \mathrm{Cl}$ & $\mathrm{p}$ value & Adjusted OR & $95 \% \mathrm{Cl}$ & $p$ value & PAR\% \\
\hline Age group (years) & & & 0.0037 & & & 0.0903 & \\
\hline$<19$ & 1.00 & & & 1.00 & & & \\
\hline $20-34$ & 2.45 & $1.49-4.02$ & 0.0004 & 2.04 & $1.19-3.51$ & 0.0098 & 51.0 \\
\hline $35-49$ & 2.60 & $1.59-4.26$ & 0.0001 & 1.94 & $1.12-3.36$ & 0.0180 & 48.4 \\
\hline $50-64$ & 2.17 & $1.26-3.74$ & 0.0049 & 1.47 & $0.80-2.70$ & 0.2081 & \\
\hline$\geq 65$ & 1.98 & $0.97-4.01$ & 0.0576 & 1.60 & $0.73-3,48$ & 0.2365 & \\
\hline Prior TB treatment & & & & & & 0.0022 & \\
\hline No & 1.00 & & & 1.00 & - & - & \\
\hline Yes & 2.26 & $1.69-3.01$ & 0.0000 & 1.70 & $1.21-2.39$ & 0.0022 & 41.2 \\
\hline HIV infection & & & 0.0070 & & & 0.0362 & \\
\hline Negative & 1.00 & & & 1.00 & - & & \\
\hline Positive & 2.93 & $1.45-5.92$ & 0.0026 & 3.19 & $1.31-7.73$ & 0.0102 & 68.3 \\
\hline Not tested & 1.00 & $0.75-1.33$ & 0.9987 & 1.08 & $0.76-1.51$ & 0.6564 & \\
\hline \multicolumn{8}{|l|}{ Drug regimen } \\
\hline $\mathrm{PZA}+\mathrm{INH}+\mathrm{RMP}$ & 1.00 & & & & & & \\
\hline $\mathrm{PZA}+\mathrm{INH}+\mathrm{RMP}+\mathrm{BEM}$ & 2.13 & $1.46-3.10$ & 0.0001 & & & & \\
\hline \multicolumn{8}{|l|}{ Literacy } \\
\hline Yes & 1.00 & & 1.00 & 1.00 & - & - & \\
\hline No & 1.71 & $1.26-2.32$ & 0.0005 & 1.55 & $1.08-2.22$ & 0.0160 & 35.5 \\
\hline \multicolumn{8}{|l|}{ Income of head of household } \\
\hline (times the minimum wage) & & & 0.0740 & & & & \\
\hline$\geq 2$ & 1.00 & & & & & & \\
\hline$<2$ & 1.52 & $1.00-2.32$ & 0.0470 & & & & \\
\hline Unknown & 1.58 & $1.05-2.36$ & 0.0257 & & & & \\
\hline Alcohol consumption & & & 0.0248 & & & 0.0061 & \\
\hline Non-drinker & 1.00 & & & 1.00 & - & - & \\
\hline Social drinker & 1.08 & $0.80-1.46$ & 0.8383 & 1.14 & $0.81-1.59$ & 0.4571 & \\
\hline Alcoholic & 1.79 & $1.21-2.66$ & 0.0079 & 2.06 & $1.32-3.21$ & 0.0014 & 51.0 \\
\hline Health district & & & 0.0000 & & & 0.0000 & \\
\hline I & 1.00 & & & 1.00 & & & \\
\hline II & 1.56 & $0.97-2.51$ & 0.0645 & 1.62 & $0.94-2.81$ & 0.0819 & \\
\hline III & 1.15 & $0.68-1.94$ & 0.6062 & 1.16 & $0.63-2.16$ & 0.6287 & \\
\hline IV & 0.39 & $0.21-0.72$ & 0.0028 & 0.33 & $0.15-0.70$ & 0.0043 & \\
\hline V & 1.36 & $0.83-2.23$ & 0.2139 & 1.87 & $1.06-3.31$ & 0.0298 & \\
\hline $\mathrm{VI}$ & 1.67 & $0.88-3.18$ & 0.1153 & 1.83 & $0.86-3.88$ & 0.1130 & \\
\hline
\end{tabular}

are less likely to die from the disease. We believe that the material obstacles to successful treatment are such that gender-related social and cultural factors are not visible.

\section{Conclusion}

Individual and grouped outcome analysis identified the relevant risk factors for planning public health interventions, while the population-attributable risk expresses the potential benefit of such interventions. Unsuccessful outcomes are adverse health conditions for the patients themselves and are also adverse for public health, because they increase the duration of infectiousness; thus, they should also be considered together for planning effective control strategies. A large proportion of unsuccessfully treated cases could be identified at entry by screening for age group, HIV, treatment delay, prior treatment, alcoholism, illiteracy, and income, and specially targeted measures could be taken. We suggest the following strategies, based on our results and the local situation: further training of FHP personnel in TB control, awareness-raising of the need 
to tailor the activities to special case situations, for example, illiteracy; targeting the use of DOT to risk groups; establishment of a flexible referral scheme capable of handling technical and psychosocial problems, including alcoholism and stigma; and increased collaboration with the HIV/AIDS program. Further training should also

\section{Resumo}

Acompanhou-se uma coorte de casos de tuberculose que iniciou o tratamento entre maio de 2001 e julho de 2003, em Recife, Pernambuco, Brasil, com o objetivo de investigar a associação de fatores biológicos, clínicos, sociais, de hábitos de vida e acesso aos serviços de saúde com falência terapêutica, abandono e óbito, separadamente e de forma agregada. Falência do tratamento esteve associada com demora para o início do tratamento, analfabetismo e consumo de álcool. Associação com o óbito foi encontrada com grupo etário, demora para o início do tratamento, co-infecção pelo HIV e renda do chefe da família. Fatores associados ao abandono foram grupo etário, tratamento prévio para tuberculose e analfabetismo. Os fatores associados aos desfechos de forma agregada foram grupo etário, coinfecção pelo HIV, analfabetismo, consumo de álcool e tratamento prévio para tuberculose. Sugere-se, para aumentar os percentuais de cura, a capacitação continuada das equipes do Programa Saúde da Família para o controle da tuberculose, adaptação das atividades de controle para situações especiais como analfabetismo, alcoolismo e co-infecção pelo HIV, direcionando o uso da terapia diretamente observada para estes grupos de risco.

Tuberculose; Fatores de Risco; Falha de Tratamento focus on early identification and more efficient management of respiratory symptoms (patients presenting with cough of more than three weeks' duration) and decreasing the delay in initiating treatment. Research should continue to focus on the successes and limitations of these different strategies.

\section{Contributors}

M. F. P. M. Albuquerque contributed to the study design, literature review, protocol elaboration, training of field interviewers, preparation of the analytical plan, data analysis, discussion of the results, and drafting of the article. R. A. A. Ximenes contributed to the study design, protocol elaboration, training of field interviewers, preparation of the analytical plan, data analysis, discussion of results, and drafting of the article. N. Lucena-Silva participated in the laboratory work, control of bacteriological and serological tests, and discussion of the results. W. V. Souza participated in the preparation and validation of the databank and discussion of the results. A.T. Dantas contributed to the patient interviews, literature review, analysis, and discussion of the results. O. M. S. Dantas participated in the literature review, analysis, and discussion of the results. L. C. Rodrigues participated in the analysis and interpretation of the results and drafting of the article.

\section{Acknowledgements}

The authors wish to thank the Brazilian National Research Council (Conselho Nacional de Desenvolvimento Científico e Tecnológico - CNPq), British Council, and REDE-TB do Brasil for funding this study. 


\section{References}

1. Secretaria de Políticas de Saúde, Ministério da Saúde. Manual técnico para o controle da tuberculose. Brasília: Ministério da Saúde; 2002.

2. Paz AM, Siqueira MT. Avaliação da estratégia DOTS nas ações de controle na tuberculose em um centro de saúde do Recife. In: Livro de apresentação de pôsteres do 6o Congresso Brasileiro de Epidemiologia. Rio de Janeiro: ABRASCO; 2004.

3. Ruffino-Netto A, Villa TCS. Tuberculose - implantação do DOTS em algumas regiões do Brasil. Histórico e peculiaridades regionais. Ribeirão Preto: Instituto Milênio Rede TB; 2006.

4. Comolet TM, Rakotomalala R, Rajaonarioa H. Factors determining compliance with tuberculosis treatment in an urban environment, Tamatave, Madagascar. Int J Tuberc Lung Dis 1998; 2:891-7.

5. Liam CK, Lim, KH, Wong, CM, Tang BG. Attitudes and knowledge of newly diagnosed tuberculosis patients regarding the disease, and factors affecting treatment compliance. Int J Tuberc Lung Dis 1999; 3:300-9.

6. Connolly C, Davies GR, Wilkinson D. Who fails to complete tuberculosis treatment? Temporal trends and risks factors for treatment interruption in a community-based directly observed therapy programme in a rural district of South Africa. Int J Tuberc Lung Dis 1999; 3:1081-7.

7. Wobeser W, Yuan L, Naus M. Outcome of pulmonary tuberculosis treatment in the tertiary care setting-Toronto 1992/1993. Tuberculosis Treatment Completion Study Group. CMAJ 1999; 160:789-94.

8. Albuquerque MFM, Sá-Leitão CC, Campelo ARL, Souza WV, Salustiano A. Fatores prognósticos para o desfecho do tratamento da tuberculose pulmonar em Recife, Pernambuco, Brasil. Rev Panam Salud Pública 2001; 9:368-75.

9. Rabahi MF, Rodrigues AB, Mello FQ, Netto JCA, Kritski AL. Noncompliance with tuberculosis treatment by patients at a tuberculosis and AIDS reference hospital in Midwestern Brazil. Braz J Infect Dis 2002; 6:63-73.

10. Uplekar MW, Rangan S, Weiss MG, Ogden J, Borgdorff MW, Hudelson P. Attention to gender issues in tuberculosis control. Int J Tuberc Lung Dis 2001; 5:220-4.

11. Borgdorff MW, Veen J, Kalisvaart NA, Broekmans JF, Nagelkerke NJ. Defaulting from tuberculosis treatment in the Netherlands: rates, risk factors and trend in the period 1993-1997. Eur Respir J 2000; 16:209-13.

12. Anibarro L, Lires JA, Iglesias F, Vilarino C, Baloria A, Lis JM, et al. Social risk factors for noncompliance with tuberculosis treatment in Pontevedra, Spain. Gac Sanit 2004; 18:38-44.

13. Burman WJ, Cohn DL, Rietmeijer CA, Judson FN, Sbarbaro JA, Reves RR. Noncompliance with directly observed therapy for tuberculosis. Epidemiology and effect on the outcome treatment. Chest 1997; 111:1168-73.

14. Aliyu MH, Salihu HM, Ratard R. HIV infection and sputum-culture conversion in patients diagnosed with Mycobacterium tuberculosis: a populationbased study. Wien Klin Wochenschr 2003; 10:340-6.
15. Rocha M, Pereira S, Ferreira L, Barros H. The role of adherence in tuberculosis HIV-positive patients treated in ambulatory regimen. Eur Respir J 2003; 21:785-8.

16. El-Sony AI, Khamis AH, Enarson DA, Baraka O, Mustafa SA, Bjune G. Treatment results of DOTS in 1797 Sudanese tuberculosis patients with or without HIV co-infection. Int J Tuberc Lung Dis 2002; 6:1058-66.

17. Santos MAPS, Albuquerque MFPM, Ximenes RAA, Lucena-Silva NLCL, Braga C, Campelo ARL, et al. Risk factors for treatment delay in pulmonary tuberculosis in Recife, Brazil. BMC Public Health 2005, 5:25.

18. Zafran N, Hedal E, Pavlovic S, Vuckovic D, Boe J. Why do our patients die of active tuberculosis in the era of effective therapy? Tuber Lung Dis 1994; 75:329-33.

19. Souza WV. O uso de informações sócio-econômicas na construção de indicadores de situação coletiva de risco para a ocorrência de tuberculose em Olinda, Pernambuco [Dissertação de Mestrado]. Recife: Centro de Pesquisas Aggeu Magalhães, Fundação Osvaldo Cruz; 1998.

20. Dias-da-Costa JS, Gonçalves H, Menezes AMB, Devens E, Piva M, Gomes M, et al. Controle epidemiológico da tuberculose na cidade de Pelotas, Rio Grande do Sul, Brasil: adesão ao tratamento. Cad Saúde Pública 1998; 14:409-15.

21. Gonçalves H, Dias-da-Costa JS, Menezes AMB, Knauth D, Leal OF. Adesão à terapêutica da tuberculose em Pelotas, Rio Grande do Sul: na perspectiva do paciente. Cad Saúde Pública 1999; 15:777-87.

22. Antunes JLF, Waldman EA. The impact of AIDS, immigration and housing overcrowding on tuberculosis deaths in São Paulo, Brazil, 1994-1998. Soc Sci Med 2001; 52:1071-80.

23. White MC, Portillo CJ. Tuberculosis mortality associated with AIDS and drug or alcohol abuse: analysis of multiple cause-of-death data. Public Health 1996; 110:185-9.

24. Menezes AMB, Dias-da-Costa JS, Gonçalves H, Morris S, Menezes M, Lemos S, et al. Incidência e fatores de risco para tuberculose em pelotas, uma cidade do Sul do Brasil. Rev Bras Epidemiol 1998; 1:50-60.

25. Nyirenda TE, Harries AD, Gausi F, van Gorkom J, Maher D, Floyd K, et al. Decentralisation of tuberculosis services in an urban setting, Lilongwe, Malawi. Int J Tuberc Lung Dis 2003; 7(9 Suppl 1): S21-8.

26. Kangangi JK, Kibuga D, Muli J, Maher D, Billo N, N'gang'a L, et al. Decentralisation of tuberculosis treatment from the main hospitals to the peripheral health units and in the community within Machakos district, Kenya. Int J Tuberc Lung Dis 2003; 7(9 Suppl 1):S5-13.

27. Miti S, Mfungwe V, Reijer P, Maher D. Integration of tuberculosis treatment in a community-based home care programme for persons living with HIV/AIDS in Ndola, Zambia. Int J Tuberc Lung Dis 2003; 7(9 Suppl 1):S92-8. 
28. World Health Organization. Interim policy on collaborative TB/HIV activities. Geneva: World Health Organization; 2004.

29. Kang'ombe C, Harries AD, Banda H, Nyangulu DS, Whitty CJ, Salaniponi FM, et al. High mortality rates in tuberculosis patients in Zomba Hospital, Malawi, during 32 months of follow-up. Trans $\mathrm{R}$ Soc Trop Med Hyg 2000; 94:305-9.

30. Daucourt V, Elia-Pasquet S, Portel L, Petit-Carrié S, Courty G, Dupon M, et al. Follow-up of tuberculosis patients and link with HIV infection in a French district, Gironde, 1995-1996. Med Mal Infect 2000; 30:152-61.
31. Oscherwitz T, Tulsky JP, Roger S, Sciortino S, Alpers A, Royce S. Detention of persistently nonadherent patients with tuberculosis. JAMA 1997; 278:865-7.

32. Marco A, Cayla JA, Serra M, Pedro R, Sanrama C, Guerrero R, et al. Predictors of adherence to tuberculosis treatment in a supervised therapy programme for prisoners before and after release. Study Group of Adherence to Tuberculosis Treatment of Prisoners. Eur Respir J 1998; 4:967-71.

33. Tanguis HG, Caylá JA, Garcia-de-Olalla PG, Jansa JM, Brugal MT. Factors predicting non-completion of tuberculosis treatment among HIV-infected patients in Barcelona (1987-1996). Int J Tuberc Lung Dis 2000; 4:55-60.

Submitted on 11/Nov/2005

Final version resubmitted on 13/Nov/2006

Approved on 27/Dec/2006 